Choroidal metastasis is the most common intraocular malignancy in adults. A 37-year-old male patient presented with coughing. Thorax computerized tomography (CT) scan showed bilateral multiple nodules. The bronchoscopic biopsy pathology findings were compatible with squamous cell carcinoma. The patient was diagnosed with stage IV NSCLC and received $6 \mathrm{cy}$ cles of chemotherapy including cisplatin and vinorelbine. Positron emission tomography (PET) imaging revealed regression of old lesions but new metastatic lesions in the musculoskeletal system, intensive involvement in the orbital muscles of the right orbita, and increased FDG uptake (SUV max $: 3.6$ ) in the posterior parts of the upper orbita. Palliative radiotherapy was performed for metastatic bone lesions. The patient complained of blurred vision two weeks after the PET imaging. Two amelanositic lesions in the upper temporal area in the right eye were detected in the examination of the eyes. Therefore, fundus fluorescein angiography and optical coherence tomography imaging were performed, and these lesions were accepted as metastasis. These lesions were in $\mathrm{fa}$ vour of metastasis.

Key words: choroidal metastasis, nonsmall cell lung cancer, positron emission tomography.

Contemp Oncol (Pozn) 2014; 18 special issue DOI: $10.5114 /$ wo. 2014.40602

\section{Positron emission tomography is moderately useful in the diagnosis of orbital metastasis}

\author{
Celalettin Eroglu ${ }^{1}$, Dilek Unal', Neslihan Kurtul' ${ }^{1}$, Ummuhan Abdulrezzak $^{2}$, \\ M. Koray Gumu
}

\begin{abstract}
1Department of Radiation Oncology, Erciyes University Medical Faculty, Kayseri ${ }^{2}$ Department of Nuclear Medicine, Erciyes University Medical Faculty, Kayseri ${ }^{3}$ Department of Eye Diseases, Erciyes University Medical Faculty, Kayseri
\end{abstract}

\section{Introduction}

Choroidal metastasis is the most common intraocular malignancy in adults [1-3]. It is seen in patients with advanced disease and is associated with poor prognosis [4]. In non-small cell lung cancer (NSCLC), choroidal metastasis is rare $[5,6]$. Positron emission tomography (PET), which has been used in clinical practice in recent years, has proven useful in the diagnosis and following of many oncological diseases. In this case report, we aimed to emphasize the importance of PET for the diagnosis of choroidal metastasis, which is rarely seen in NSCLC.

\section{Case report}

A 37-year-old male patient presented with coughing. A chest X-ray revealed consolidation in the upper and middle zones of the left lung. Thorax computerized tomography (CT) scan showed bilateral multiple nodules, the largest of which were $24 \mathrm{~mm}$ and $16 \mathrm{~mm}$ in the upper lobe and the lower lobe of the left lung, respectively, as well as mediastinal lymph nodes, the largest of which was $19 \mathrm{~mm}$, and pericardial fluid. The bronchoscopic biopsy pathology findings were compatible with squamous cell carcinoma. 18F-fluorodeoxyglucose (FDG)-PET-CT, which is used for the staging of primary malignant lesions, revealed primary malignant lesions located centrally in the left suprahilar, bilateral supraclavicular and mediastinal metastatic lymph nodes, which were prominent in the left lung, and multiple metastases in both surrenal glands and in the skeleton (intense FDG uptake, SUV max $_{\text {val- }}$ ues: 7-13). The patient, who was diagnosed with stage IV NSCLC, received 6 cycles of chemotherapy, including cisplatin and vinorelbine. The second PET-CT imaging revealed the regression of old lesions but with new metastatic lesions in the musculoskeletal system, intensive involvement in the orbital muscles of the right orbita, and increased FDG uptake (SUV $\left.{ }_{\max }: 3.6\right)$ in the posterior parts of the upper orbita (Fig. 1). Palliative radiotherapy was performed for metastatic bone lesions. The patient complained of blurred vision two weeks after the second PET-CT imaging (i.e. approximately 6 months after the diagnosis). Contrast-enhanced cranial CT was normal. Two amelanositic lesions in the upper temporal area in the right eye were detected during examination of the eyes. Therefore, fundus fluorescein angiography (Fig. 2) and optical coherence tomography imaging were performed, and these lesions were accepted as metastasis. These lesions were in favour of metastasis. Approximately two weeks after the start of blurred vision, an increase in mass size located centrally on the left suprahilar region with obstructive pneumopathy was established in a chest CT performed because of the shortness of breath. Palliative radiotherapy for lung mass and antibiotic treatment for obstructive pneumopa- 


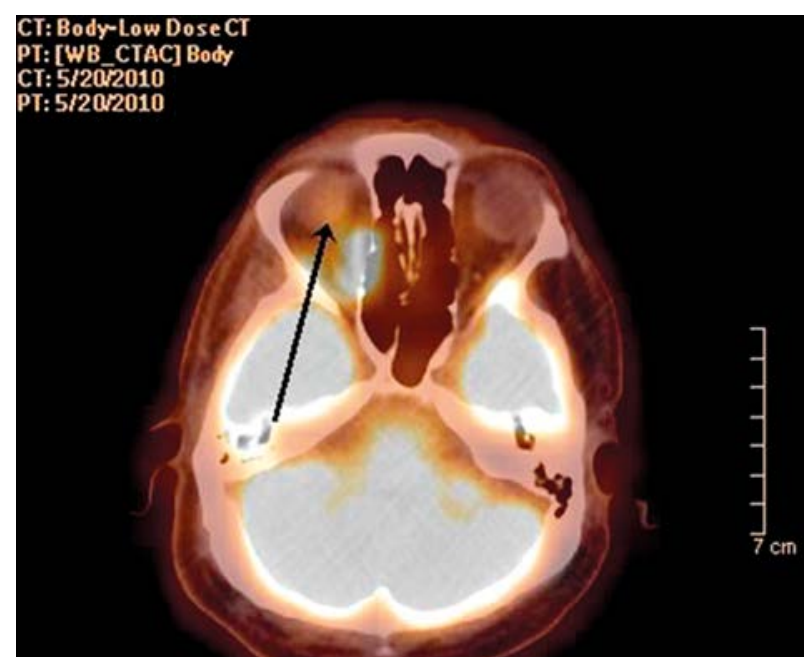

Fig. 1. PET-CT fusion image of the head revealed mild F-18 FDG uptake in the posterior aspect of the right eye-ball (arrow)

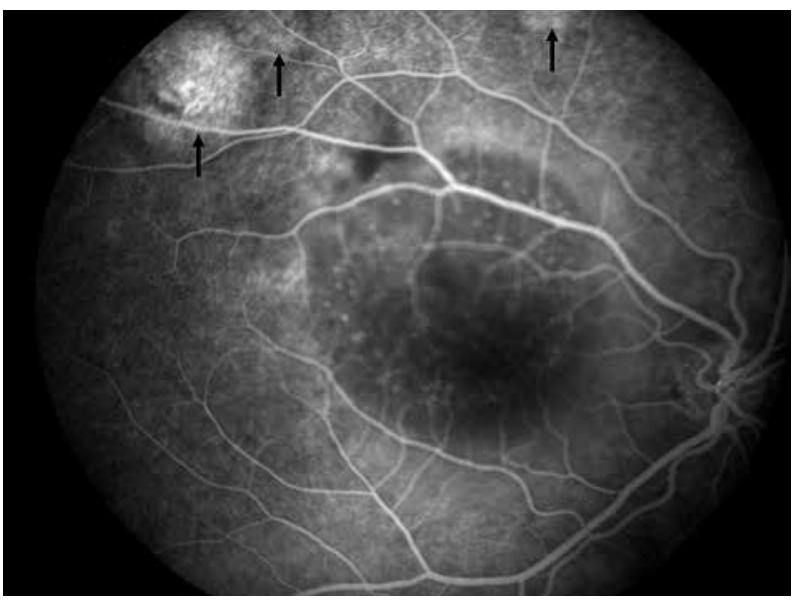

Fig. 2. The arrowheads show choroidal metastases in fundus fluorescein angiography

thy were started. However, the patient died due to sepsis on the fourth day of thoracic radiotherapy.

\section{Discussion}

Positron emission tomography is a novel, useful imaging method that is increasingly being used for the diagnosis and staging of a series of tumours, detection of recurrence and assessment of therapeutic response. A combination of PET and CT improves the diagnostic capability of the method [7, 8].

Ocular tumours may be primary or metastatic. Ocular metastases occur frequently in the choroid. Choroidal metastasis may be single or multiple. Choroidal metastasis, which is seen rarely, is most commonly seen in breast and lung cancers. The incidence of ocular metastases of lung cancers has been reported to be $2-7 \%$ in the literature [9]. The diagnosis of ocular metastases is based on clinical findings supported by imaging techniques [9]. Ultrasonography reveals diffuse choroidal thickening with increased echogenicity and provides local extent of the tumour and may mimic amelanotic melanoma. However, it cannot cer- tainly differentiate between the primary tumour and metastasis [10]. 18F-fluorodeoxyglucose PET/CT is a sensitive imaging modality to localize choroidal lesions. It provides the opportunity to detect small lesions or lesions in other organs not visible with other imaging modalities. In addition, it can help to differentiate metastatic from benign lesions and can detect metastatic lesions obscured by other processes or CT artefacts [11]. On the other hand, physiological FDG uptake in the ocular muscles is often seen, and, therefore, it may interfere with the detection of such small intraocular foci. In addition, it may not differentiate between choroidal melanoma and metastasis. However, in a known case of cancer with multi-organ involvement, such as in the present patient, the method virtually identifies intraocular metastasis.

Although the clinical findings refer to ocular metastasis, in this patient orbital metastasis was detected in the PET-CT evaluation performed to assess the response to the treatment of primary cancer before the appearance of its clinical findings.

Survival after the development of orbital metastasis is poor [9]. Consistent with this observation, this patient died within one month after the detection of orbital metastasis. Orbital metastasis should be kept in mind in the presence of increased FDG orbital uptake in PET-CT in patients with NSCLC, even in the absence of its clinical signs and symptoms.

Authors declare no conflict of interest.

\section{References}

1. Ferry AP, Font RL. Carcinoma metastatic to the eye and orbit. I. A clinicopathologic study of 227 cases. Arch Ophthalmol 1974; 92: 276-86.

2. Shields CL, Shields JA, Gross NE, Schwartz GP, Lally SE. Survey of 520 eyes with uveal metastases. Ophthalmology 1997; 104: 1265-76.

3. Kreusel KM, Wiegel T, Stange M, Bornfeld N, Hinkelbein W, Foerster $\mathrm{MH}$. Choroidal metastasis in disseminated lung cancer: frequency and risk factors. Am J Ophthalmol 2002; 134: 445-7.

4. Koçak Z, Tabako lu E, Benian O, Bayir G, Unlü E, Uzal C. Bilateral choroidal metastases as an initial manifestation of small-cell carcinoma of the lung. Tuberk Toraks 2006; 54: 61-4.

5. George B, Wirostko WJ, Connor TB, Choong NW. Complete and durable response of choroid metastasis from non-small cell lung cancer with systemic bevacizumab and chemotherapy. J Thorac Oncol 2009; 4: 661-2.

6. Kim SW, Kim MJ, Huh K, Oh J. Complete regression of choroidal metastasis secondary to non-small-cell lung cancer with intravitreal bevacizumab and oral erlotinib combination therapy. Ophthalmologica 2009; 223: 411-3.

7. Kula Z, Szafrańska-Komarowska I, Małkowski B. Utility of positron emission tomography in pediatric oncology. Contemp Oncol 2011; 15: 20-6.

8. Kula Z, Jóźwicki W, Zegarski W. Benign mesocolon schwannoma in PET/CT and immunohistochemistry assessment: a case report. Contemp Oncol (Poznan)2012; 16: 360-2.

9. Asteriou C, Konstantinou D, Kleontas A, Paliouras D, Samanidis G, Papadopoulou F, Barbetakis N. Blurred vision due to choroidal metastasis as the first manifestation of lung cancer: a case report. World I Surg Oncol 2010; 8: 2.

10. Solav S, Bhandari R, Sowani A, Saxena S. Choroidal metastasis from carcinoma of breast detected on F18-FDG PET CT scan: 
A case report and review of literature. Indian J Nucl Med 2010;

25: 160-3.

11. Donaldson MJ, Pulido JS, Mullan BP, Inwards DJ, Cantrill H, Johnson MR, Han MK. Combined positron emission tomography/computed tomography for evaluation of presumed choroidal metastases. Clin Experiment Ophthalmol 2006; 34: 846-51.

\section{Address for correspondence}

\section{Dr. Dilek Unal}

Erciyes Üniversitesi Tip Fakültesi

M. Kemal Dedeman Onkoloji Hastanesi

38039, Kayseri, Türkiye

tel. 90-3522076666, fax 90-3524375807

e-mail: dilekunaldr@gmail.com

Submitted: 9.08 .2012

Accepted: $\quad 7.11 .2012$ 